\title{
CORNISH KNITTING PATTERN SERIES
}

\section{JENNIFER NIGHTINGALE*}

\section{Abstract}

The Cornish Knitting Pattern Series is a collection of $16 \mathrm{~mm}$ animation landscape films that use a single frame production technique to translate Guernsey knitting patterns into film. In doing so, the films set up a structural relationship between that of a knitted stitch and a frame of filmdrawing out analogies between both forms of production. The article considers methods and processes of the films' production, including the role of the film charts and location-as-editing system. The film charts are explored as examples of an approach to systems-based editing and a single frame production in the context of experimental film. They are also discussed as visualizations of the knitting patterns; pragmatic preproduction material; notation documentation and retrospectively a significant aid to reflection on the work carried out. Key aspects of the film series such as how gesture, landscape and film are 'knitted together' in the film as a material object, are also highlighted. Further to this the article explores how these aspects reveal readings of the films' relationship to Landscape, knitting practices and the historical and cultural aspects of the Cornish Guernsey patterns.

Keywords:16mm film; animation; experimental film; artists' film; film diagrams: Cornish Guernsey knitting patterns: landscape:editing system:frame: textiles 


\section{Cornish Knitting Pattern Series}

This article deals with a series of Landscape films titled the Cornish Knitting Pattern Series that has come out of my current $\mathrm{PhD}$ by practice. The series use single frame production methods and a $16 \mathrm{~mm}$ bolex camera, to create a structural relationship between a frame of film and a knitted stitch. The films use Cornish Guernsey knitting patterns in order to set up 'location' as editing system and, in doing so, highlight the historical and cultural aspects of the patterns.

These films also sit in the broader context of my artist film practice. This practice usually deals with ideas of frame, gesture, and technology by reconfiguring conventional filmmaking processes to present new relationships between the filmmaker, camera and subject.

As the practice-based research is significantly methodologically driven, the article will be focusing on the process of production and exploring the role of the filming charts used. It will also be aiming to draw out threads of research and reflection that look to the historical and cultural nature of the project. In doing so, it hopes to illuminate the implicit nature of these elements as a guiding force or inspiration within the work and my role as a filmmaker. This will start by introducing the Cornish Guernsey Knitting Patterns before moving on to my translation of them into film.

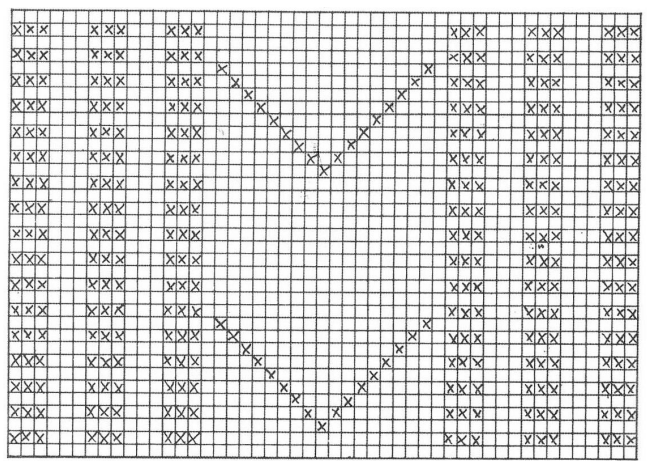

Figure 1
Figure 1 is an example of a Cornish Guernsey Knitting pattern (titled Porthleven) and a detail of a knitted Guernsey that uses the pattern in figure 2. The pattern chart on the left has been scanned from Mary Wright's Cornish Guernsey's and Knit-frocks (2008) originally published in 1979. This book has been a key resource for my project as it is the first significant attempt to document the Cornish patterns and their history. It builds on documentation of Guernsey's of North England and Scotland in an earlier book by Gladys Thompson titled Guernsey and Jersey Patterns (1955).

The patterns drawn up by Mary Wright have been titled according to locations where the patterns where first used. These Cornish Guernsey patterns use a combination of knit and purl stitches to create texture and pattern on the surface of the knitted garment. The knitting patterns documented in the book fall into two camps the first being patterns that seem to represent features from the landscape and the second patterns that create textural interest. Those patterns representing the features of the landscape often create zig-zags reminiscent of Cornish cliff paths, images of nets or rope that the knitters would have seen in the harbours, or in the case of the 'Looe: Eddystone pattern' the Looe lighthouse-nine miles off the coast of Plymouth.

In Mary Wright's pattern charts the blank squares are knit stitches and the squares marked with a ' $x$ ' are purl stitches.

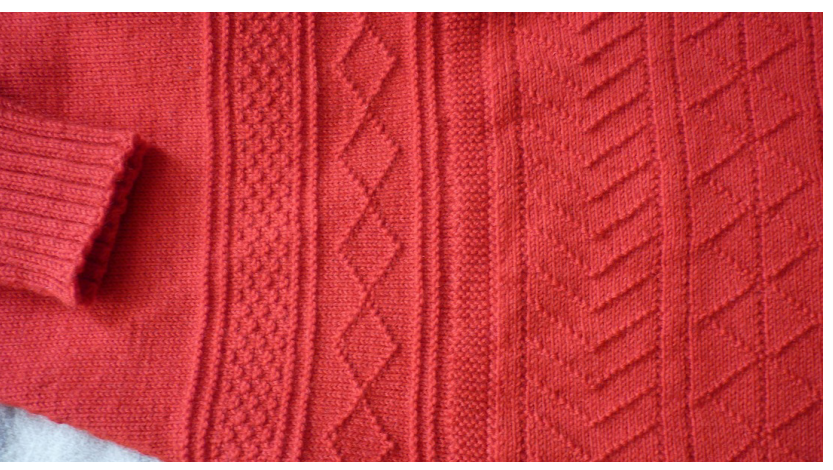

Figure 2 


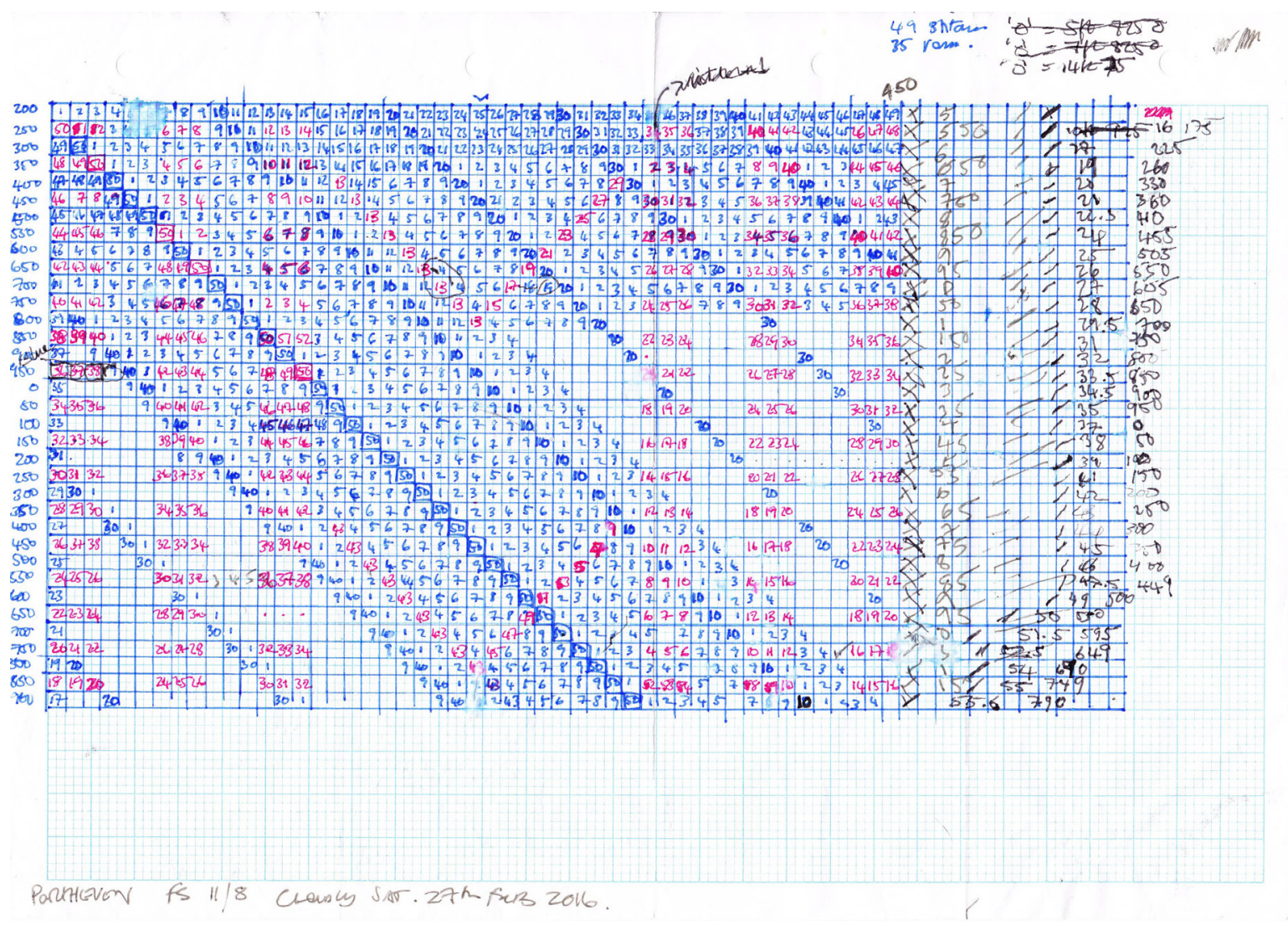

Figure 3

The Cornish knitting patterns are based on combination of knit and purl stitches creating patterns and textures that come about by exploiting the properties (flat and raised) of the knit and purl stitch. These two stitches are the foundation of knit fabric. On the right side of the fabric (the knit side) this can be seen as many interlocking v's that sit flat, on the wrong side of the fabric this appears as interlocking ' $u$ ' shaped bumps that sit raised. The purl stitch is therefore a reverse of the knit stitch and the yarn is looped in the opposite direction to create it.

The patterns as combinations of knit and purl stitches is fundamental in my translating of the patterns into film as it is these two different stitches that I equate to two different camera positions in the landscape when filming. This is what allows the structural relationship between a frame of film and a knitted stitch to be formed. Figure 3 shows the translation of the Porthleven knitting pattern into an editing chart for the filming

The film charts assign each stitch from the knitting pattern to a frame of film. Knit stitches are in blue and purl in red. These film frames are individually numbered (in this pattern there are 1715 stitches (49 stitches and 35 rows) and of course the same number of frames in the film. In the first instance these charts focused on the precise translation of the knitting 


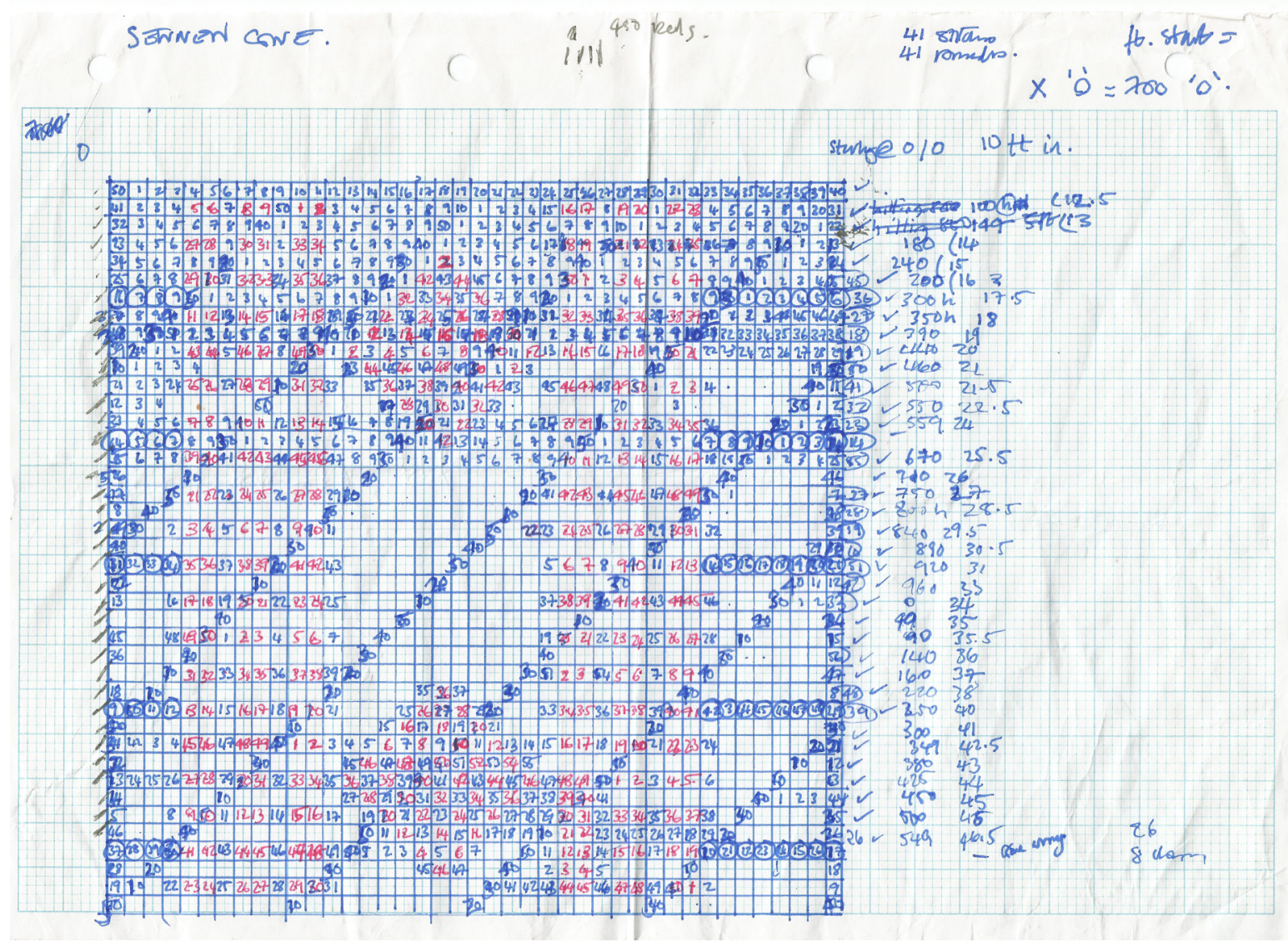

Figure 4

patterns into films. It is notable at this stage that in both instances-knitting pattern and film charts-are instructional in nature. Both are drawn up to be followed by a maker who concurrently wants to know the visual look of the completed pattern, as well as how to proceed in producing it.

At first the charts had the practical use of keeping track on individual exposures in the pro-filmic event. Retrospectively however they have been a major source of refection and documentation on the film projects production. The gridded format links the charts back to their original source of the knitting pattern chart of Mary Wright-the gridded chart being a common method of notating knitting pattern instruction. Also retained is the designation of knit and purl stitches seen on the film charts as red or blue numbered frames. Both of the above were determined before the production took place but in addition to the preproduction marks there are others made during production that reveal elements of the pro-filmic event such as the marking of exposure readings, frame and footage counter readings (Figures 4 and 5) but also notation of mistakes and documentation of the weather (seen in the rain streaked film chart of Polperro - Figure 6). 


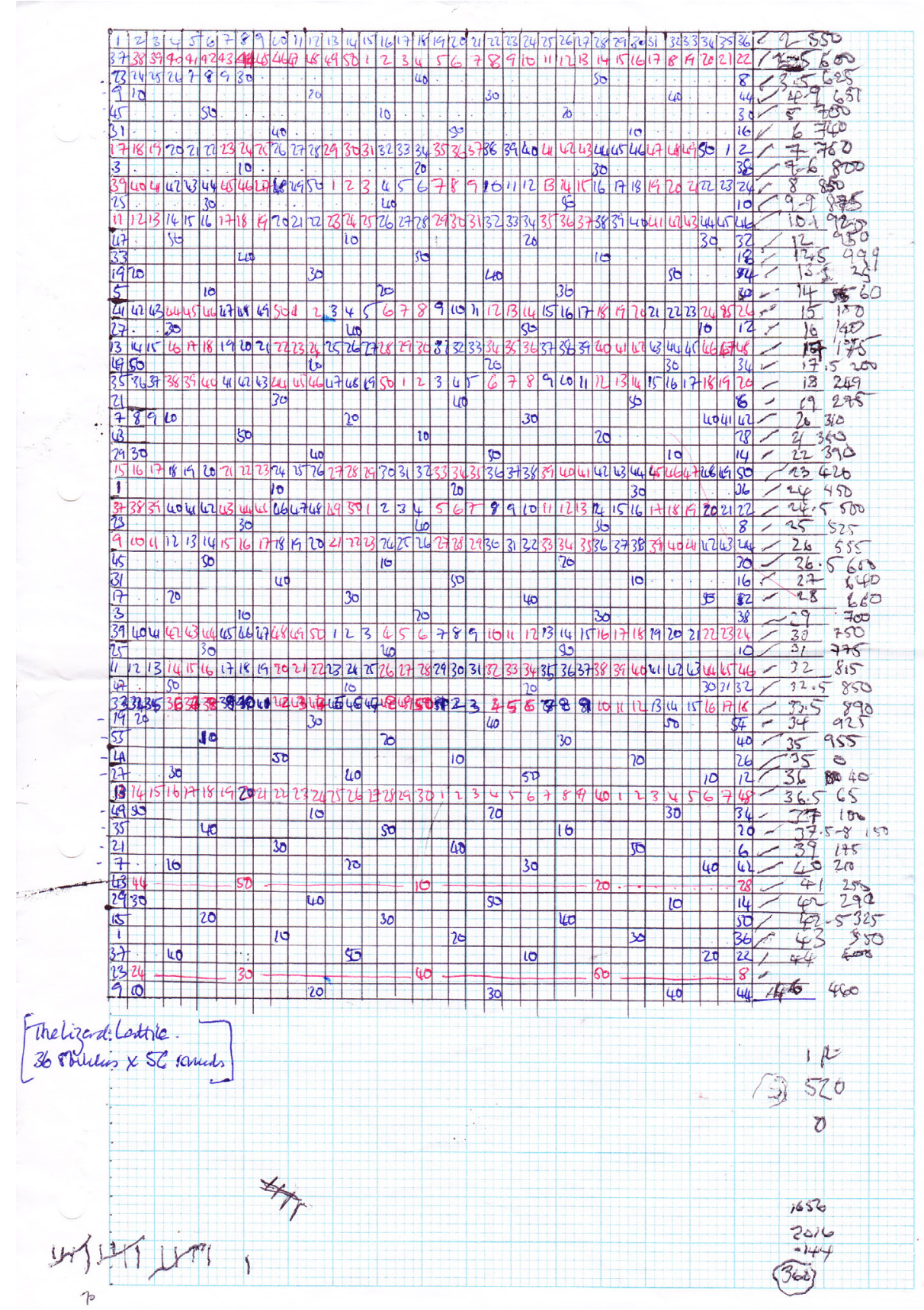

Figure 5 


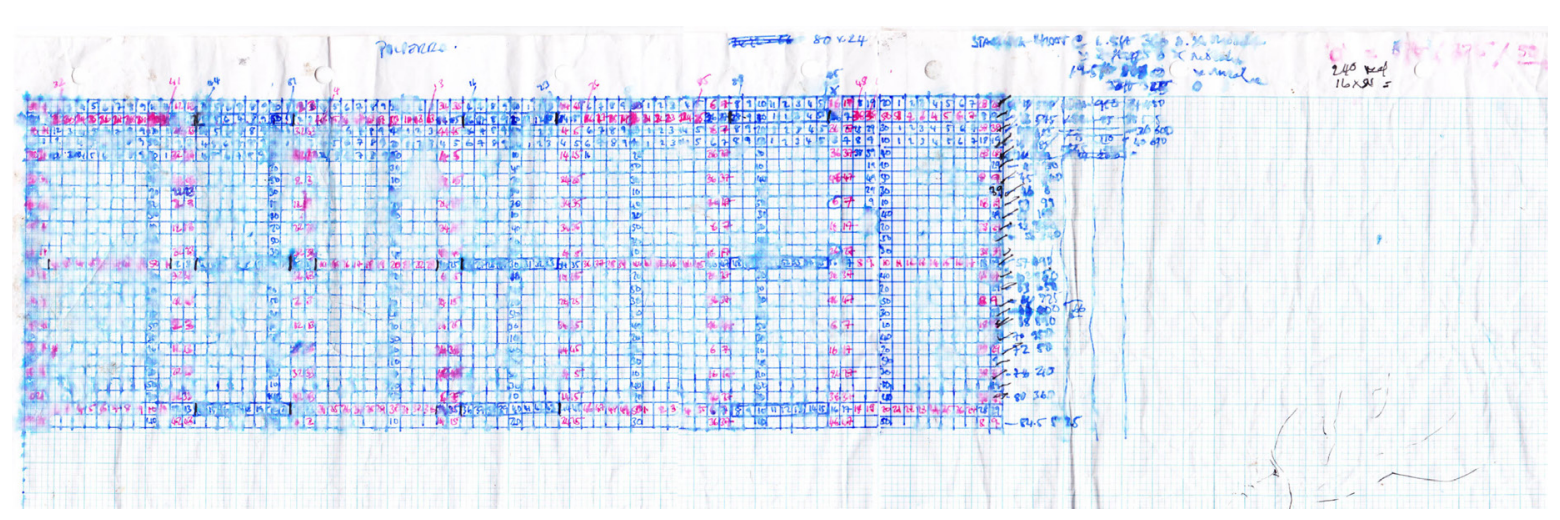

Figure 6

This use of charts to think through film work is not unique (storyboards being one such film industry convention) and within the context of experimental film other makers such as Vertov (whose diagrams can be viewed on the Austrian Film Museum website), Kurt Kren (Hamlyn et al. 2016 pp.164-170), and Rose Lowder (2018) have all thought their films conceptually -and/or - visually by the use of shooting diagrams. In the case of Kren and Lowder, the resulting films also used single frame production and a Bolex camera. In addition, Vertov's films used precise 'to the frame' editing and metric editing approaches. It is not surprising therefore that the Cornish Knitting Patterns share these production approaches. The role of film charts in the Cornish Knitting pattern extends those by Lowder and Kren. The Cornish Knitting pattern charts are not only editing plans or notation but translation artefacts cementing the relationship between the patterns source (knitting patterns) and the filmmaking process. As a filmmaker and a knitter, the film charts have potential for dual use, they are tools of production from which the outcome could be fabric or film. At the point of use by the maker, the Cornish Knitting Pattern film charts straddle the disciplines and testify to the possibilities of the analogy between film and textiles practice.
The Cornish film series similar to Kren and Lowder also uses a single frame production method and a Bolex camera. This is a method whereby the motor of the camera is disengaged and each frame is individually exposed, rather than at the conventional $24 x$ a sec if I were shooting using the cameras motor. The Bolex allows individual frames on a $16 \mathrm{~mm}$ filmstrip to be exposed by disengaging the motor and using the single frame release on the side of the camera.

My method of single frame production on location involves positioning the Bolex camera in two different places within the landscape (Figure 7), one representing the knit stitches and one representing the purl. From here the film's production commences. Starting at frame ' 0 ' and following the filming chart, each knit frame is exposed in sequence, leaving the purl frames unexposed. The film is then re-wound in the camera and the camera is repositioned in the location. Then, starting again at frame ' 0 ', every purl frame is exposed filling the unexposed gaps from the first round of shooting. If there is a slip-stitch or cable stitch in the knitting pattern this method is then repeated a third time. When complete (apart from the chemical development of the film stock) I have completed the production of the film. The precise sequencing of frames can, of course, be done in digital editing software or in analogue via an optical printer. ${ }^{1}$ However the site-specific nature of the

1 An optical printer is a machine that prints positive films from original film negatives and therefore would allow the filmmaker to exposure individual frames from a film negative re-ordering them onto a positive film print. 


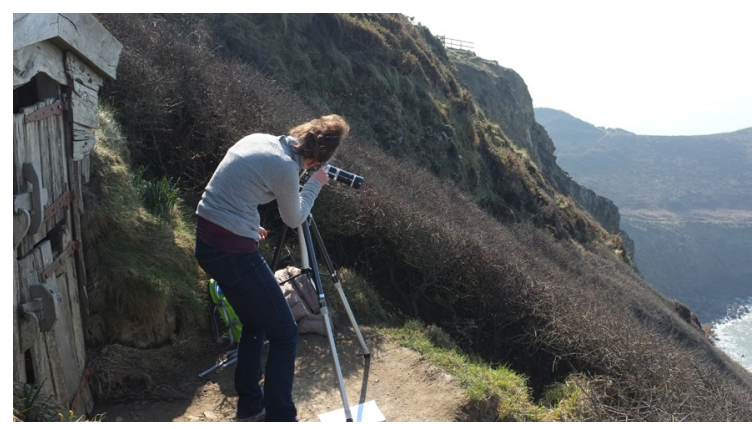

Figure 7

films production is an important aspect of the work, as for me it asserts my role as a maker and foregrounds the relationship that the patterns have to the locations through a physical gesture of production-a re-embedding of the knitting patterns into landscape.

Having translated the knitting patterns into editing charts camera positions are chosen to represent each knit and purl frame. This was inevitably done on location and, retrospectively, different approaches can be seen emerging. Firstly, these were to consider the landscape in accordance with the knitting pattern's cultural/historical associations and secondly in terms of its geological shape or man-made elements.

An example of the first approach can be seen in the production of Polperro: Snake Cable, where I use a photograph (figure 8) of Jane Joliff knitting on the under cliff in Polperro, to suggest to me a camera position from which the Polperro film would be shot. The photograph, taken in 1904, documents the practice of women knitting outside, in and around the harbour-it shows a knitter standing on the path overlooking Peak Rock in Polperro. The ball of wool, which she is knitting from, is skewered on a fence post in front. We see at her waist a knitting stick (sometimes called a knitting fish, in Polperro called a knitting shade) attached to her belt and the surplus weight of the knitted garment tucked into her apron. This is an ideal way for knitting standing up, as the knitter is liberated from weight of the garment usually held in the lap of the

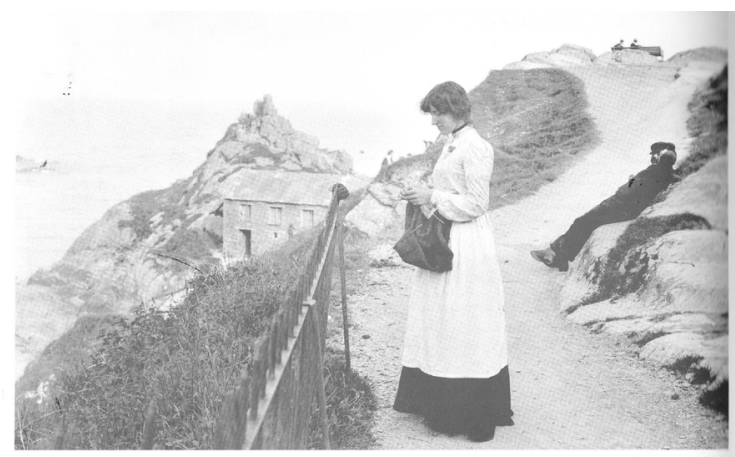

Figure 8

seated knitter and the needle is held in place by the knitting stick, allowing the knitter to use their right hand to loop the yarn faster. This would have been important to such a knitter, as the knitting was a form of paid labour through which they helped sustain their families. This industry would be on top of knitting garments unique for their family (what Joanne Turney refers to as 'knitting as a sign of the familial') (2009, p.55).

It is worth noting here that many of the research documents used by Mary Wright to archive the patterns were photographs (many of which are included in her book). For example, a major resource were the photographs of Lewis Harding an early photography pioneer living in Polperro (many of these photographs are archived in the Polperro Museum). Working from the photographs, Wright's process of documenting the patterns was to study the Guernsey's in the images and replicate the patterns in knitting. It was through this research method that Wright was able to establish the reasoning behind the knitters working outside-the Polperro fisherman's cottage windows would not have allowed enough light inside to complete the intricate stiches. This research method is reminiscent of the act of filmmaking, as both re-imagines the patterns by re'integrating them back into the location where they were first produced.

Other research took the form of interviews. It was necessary for Wright to draw on these types of research as historically the patterns were not written down but would have been 


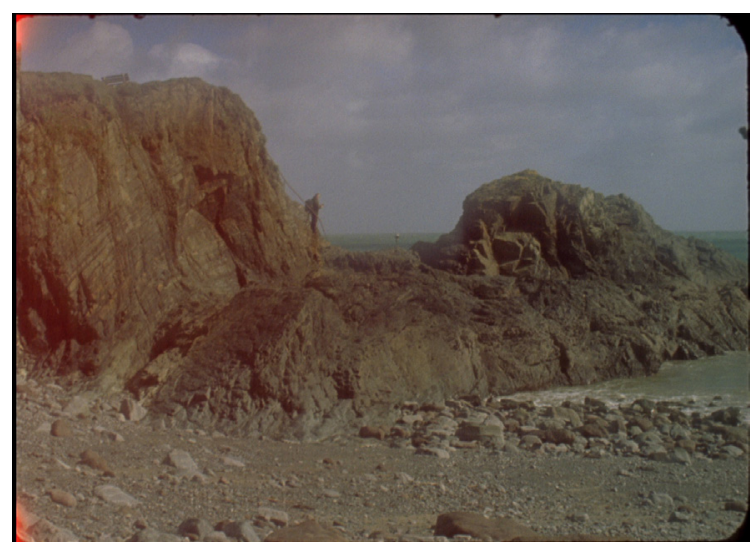

Figure 9

passed inter-generationally through families. A quote from an interview conducted with an elderly lady by Wright highlights the intergeneration activity of knitting the patterns and the skill of the young knitters: "There were nine maids in our family; the little ones knitted the 'trails' the bigger ones knitted the plain bits and Mother did the pattern" (2008 p.21)

The patterns themselves where created and adapted by the women that knitted them-they were 'live' rather than static, developing and changing through each generation. This makes me think back to the mistakes (or fallible human gestures) in the films production. As in the development of the knitting patterns, alterations/mistakes made in production open a methodologically driven process to happenstance. In the film series the mistakes and the immediate decisions made in response to the site (for example camera position, when to make an exposure) allows the films to develop and reveal landscape-and also activities, movements within it-in unexpected ways. This elevates the films from purely mechanistic instructional outcomes and creates a sense of the dialectic relationship set up in the production process-of camera, filmmaker and subject. An example of this would be the movements of tides and people in The Lizard Lattice (Figures 9 and 10).

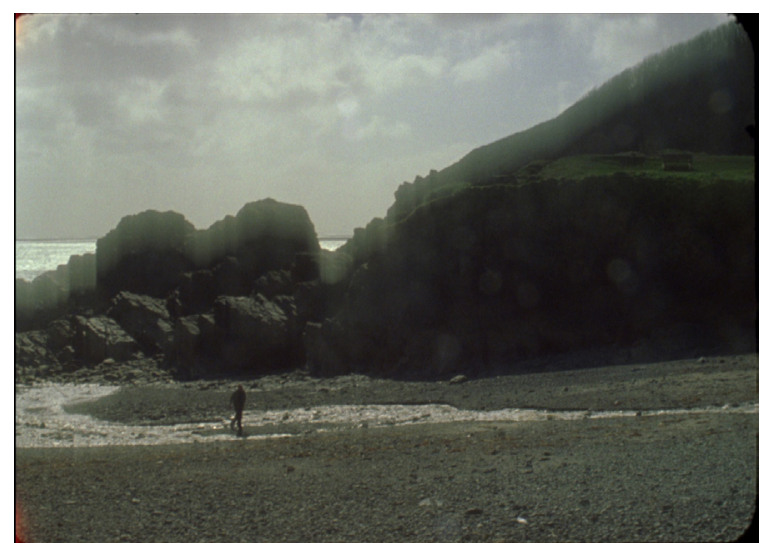

Figure 10

There are also a number of films in the series that show a second approach that I took in considering how to frame a location, this was to consider landscape in terms of its geological shape or man-made elements (for example natural rock formations and piers). Again, the Lizard Lattice is one such example. This film was shot in Cadgwith, a traditional fishing harbour near the Lizard. One of the remarkable aspects of the location is the significant rock formation that divides the space into two, on one side a natural beach and on the other a harbour. The placement of the camera was inspired by the rock formation. The film still on the right shows a 'knit' frame from the film and the left still a 'purl' frame. When the two framings are sequenced using single frame animation-the camera position moves on a plumb line anchored at the point the rocks enter the sea. (I like to consider this as a re-configuration of a pan - instead of the camera pivoting on its axis, it is the camera that moves on an axis point within the subject in frame). This privileges the landscape as a guiding force in the film's production. A further example would be St Ives: Background slip-stitch this film highlights man-made elements of the landscape and focuses on the walk-ways that lead down to the harbour. These walk-ways were access points to the harbour from the fishermen's houses or buildings used in the fishing industry (and still bear names that reference their former use e.g. Fish street). The visual effect of the walkway's in the film is that they re-frame the harbour through the 


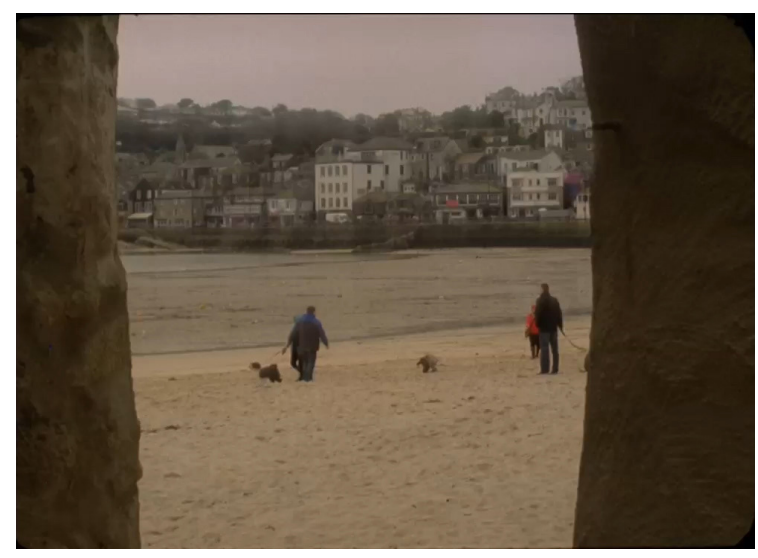

Figure 11

architecture of the town imposing another frame within in the film frame (Figures 11 and 12).

The Cornish Knitting Patterns film series intends to re-embed Cornish Guernsey knitting patterns back into the landscape which inspired them and in doing so gesture, landscape and film are 'knitted together' as a material object that is the outcome of this process. It also highlights the linear and durational aspects of both practices (knitting and film) thereby extending the analogy between the two. This analogy and subsequent processes have the potential to reveal elements that extend beyond the methods of the films' production. One such element would be how representations of time reveal natural and man-made rhythms in the Landscape of the Cornish Coast and patterns of activity (tides, tourism). Or how the films illuminate ideas of female labour in the approach taken to create an equivalent between the camera position used in Polperro: Snake Cable (2016) and the position of a Cornish Guernsey contract knitter (Jane Joliff). These ideas are not explicit in the work but have inspired the thinking behind the film series. They reveal the way in which the Cornish Knitting Pattern Series could shed light on subjects within the broader contexts of cultural and historical studies, creative practices that take Landscape as their subject, and theories of film language.

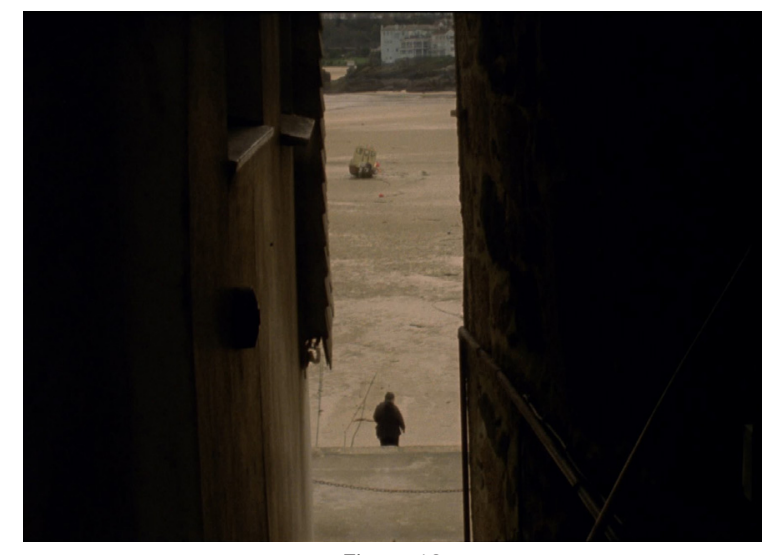

Figure 12

\section{References}

HAMLYN, N., editor, PAYNE, S., editor and REES, A.L., 2016. Kurt Kren : structural films / edited by Nicky Hamlyn, Simon Payne, and A.L. Rees. Bristol : Intellect, 2016.

LOWDER, R., 2018. Bouquets 11-20: Notebooks, Rochester, NY: VSW Press.

THOMPSON, G., 1969. Guernsey and jersey patterns.] Patterns for guernseys and jerseys. London: London : Batsford, 1969.

TURNEY, J., 2009. The culture of knitting / Joanne Turney. English ed edn. Oxford: Oxford: Berg, 2009.

WRIGHT, M. (2008), Cornish Guernseys and Knit-Frocks, Clifton-upon-Teme: Polperro Heritage Press. 
ANIMATING POETRY: WHOSE LINE IS IT ANYWAY? SUSAN J. HANNA 